\title{
Itinerários terapêuticos de sujeitos com sintomas anoréxicos e bulímicos
}

\author{
Therapeutic itineraries of individuals \\ with symptoms of anorexia and bulimia
}

${ }^{1}$ Faculdade de Medicina, Universidade Federal de Minas Gerais. Av. Prof. Alfredo Balena 190, Santa Efigênia. 30130-100 Belo Horizonte MG Brasil. bernadetec59@gmail.com

${ }^{2}$ Faculdade de Medicina, Universidade Federal de São João del-Rei. São João delRei MG Brasil.

${ }^{3}$ Faculdade de Ciências Humanas, Universidade FUMEC. Belo Horizonte MG Brasil.
Abstract The scope of this study is to identify and contextualize aspects of the therapeutic itineraries of patients treated at a university medical clinic specialized in nervous anorexia and bulimia. For this purpose, an attempt was made to reconstitute the succession of events triggered in 20 respondents and their families with the classification of anorexia and bulimia as "health problems." The narratives were analyzed in order to link the individual experiences and the social context of their occurrence (organization of health services, characteristics of treatment and medical knowledge and characteristics of contemporary subjectivity), in light of the theoretical studies of Public Health and Psychoanalysis. Data analysis revealed that these itineraries arise from connections and disconnections between two distinct approaches: one that organizes the management of patients and the other governing the conduct of health institutions and families. If the latter presuppose a quest for health, this is not what primarily concerns the individuals in question. Their refusal to moderate their own eating disorders is notable on their itineraries, and indicates the functionality of those practices. Such practices play a part in the reconstruction of their self-images.

Key words Mental health, Anorexia, Bulimia, Healthcare-seeking behavior, Power (psychology)
Resumo $O$ objetivo deste estudo foi identificar e contextualizar as características dos itinerários terapêuticos de pacientes atendidos em um ambulatório universitário, especializado nas anorexias e bulimias nervosas. Para isso, buscou-se reconstituir, junto a 20 entrevistados, a sucessão de movimentos desencadeados neles e em seus próximos pela classificação das práticas anoréxicas e bulímicas como "problemas de saúde". As narrativas foram analisadas de forma a vincular as experiências individuais e o contexto social de sua ocorrência (organização dos serviços de saúde, características da prática e do saber médico, características da subjetividade contemporânea), tendo como referencial teórico estudos da Saúde Coletiva e da Psicanálise. A análise dos dados revelou que esses itinerários são tecidos a partir de conexões $e$ desconexões entre duas lógicas distintas: uma que organiza a conduta dos pacientes e outra que rege as condutas das instituições de saúde e das famílias. Se essas últimas pressupõem uma busca pela saúde, isso não é o que ocupa prioritariamente os sujeitos em questão. A recusa destes em moderar suas restrições alimentares marca os itinerários e indica a funcionalidade dessas práticas. Elas participam de um trabalho de recomposição da imagem do eu.

Palavras-chave Saúde mental, Anorexia, Bulimia, Comportamento de procura de cuidados de saúde, Poder (psicologia) 


\section{Introdução}

Nesse artigo apresentamos uma pesquisa que se interessou por investigar os itinerários terapêuticos de sujeitos com diagnóstico de anorexia ou de bulimia nervosas.

$\mathrm{O}$ acesso a um ambulatório universitário destinado a pacientes com esse diagnóstico viabilizou a realização da investigação, não só nos colocando em contato com sujeitos dificilmente localizáveis de outra forma, como também permitiu vislumbrar, através de relatos da equipe do serviço, a existência de itinerários, no mínimo, conturbados.

A análise do material coletado nos levou a localizar atitudes, motivos, justificativas, acontecimentos, conexões e desconexões que buscamos contextualizar, tanto a partir de estudos psicanalíticos sobre as subjetividades e os sintomas contemporâneos, quanto a partir de estudos sobre as práticas e os saberes da área da saúde.

Os itinerários estudados inscrevem-se quase inteiramente no campo dos serviços de saúde, mas, constatamos também, ainda que raramente, a existência de inscrições religiosas para essas práticas alimentares. Quanto a estas inscrições, nossos dados foram insuficientes para uma análise, tendo em vista que o acesso aos entrevistados se fez mediado por um ambulatório médico, o que já selecionou os sujeitos.

Do ponto de vista psiquiátrico, as anorexias e as bulimias são definidas como síndromes graves, caracterizadas por perturbações no comportamento alimentar, associadas a distorções da imagem corporal ${ }^{1}$. Elas afetam, sobretudo, adolescentes e adultos jovens do sexo feminino, causando prejuízos físicos, psíquicos e sociais que impactam tanto os pacientes quanto os serviços de saúde pública. A anorexia é considerada a terceira doença crônica mais prevalente na adolescência e, entre todos os transtornos psiquiátricos, é o que apresenta as maiores taxas de mortalidade ${ }^{1,2}$.

Estima-se que a prevalência de anorexia nervosa entre mulheres jovens ocidentais varia de $0,3 \%$ a $0,9 \%$ e a de bulimia nervosa de $1 \%$ a $2 \%$. Há diferenças importantes na distribuição entre os gêneros, com razão homem/mulher que varia de 1:10 a 1:15 para anorexia e, de 1:15 a 1:20, para bulimia. Pesquisadores sugerem, no entanto, que as taxas de prevalência desses quadros estejam subestimadas, seja por dificuldades metodológicas, seja por não incluírem as síndromes parciais ou os comportamentos de risco para o desenvolvimento de transtornos alimentares ${ }^{1,3}$.
Para além desses dimensionamentos, este estudo busca contribuir para o enfrentamento do desafio que a ocorrência de sintomas desse tipo vem apresentando aos profissionais de saúde, convidando a uma reflexão sobre os vínculos entre essas práticas alimentares e a sociedade em que elas ocorrem. Se a anorexia e a bulimia sempre existiram, nota-se que, hoje, elas se prestam a novos usos, gerando inclusive agrupamentos, e se apresentam como respostas dos sujeitos a dificuldades subjetivas nos processos de construção social das individualidades ${ }^{4}$. Apreender os novos usos dessas práticas alimentares parece estar na base da possibilidade de sua adequada abordagem.

O presente estudo traz elementos para entender o que, no nível individual e no institucional, se conjuga para a produção dos desencontros verificados nos itinerários pesquisados. Compondo com outras pesquisas a respeito dessas práticas ${ }^{5,6}$, nossas investigações nesse campo buscam estudar, por um lado, a forma e os motivos específicos pelos quais esses sujeitos subtraem-se às estratégias de socialização, sejam elas médicas, nutricionais, escolares ou familiares, para dar lugar ao descontrole e à compulsão. Por outro, procuramos entender a produção contemporânea desses sintomas como efeitos, não desejados e ainda sem controle, dessas mesmas estratégias de socialização.

Entendemos, a partir das pesquisas de M. Foucault, que a socialização se fez, desde o século XVII, sob a égide de um poder que investiu na gestão dos corpos e da população, no sentido da maximização de suas potencialidades, constituindo-se como campo de investimento de capitais e controle social. Calcado nos saberes científicos, o assim chamado biopoder se concretizou a partir da progressiva substituição da autoridade do soberano pela disseminação da lei na forma da norma, pelo tecido social. Nesse formato, o biopoder estende sempre mais seu campo de regulamentação ${ }^{7}$.

Em nosso horizonte, perfila-se a hipótese de que esse processo de substituição da lei pela norma produz, na contemporaneidade, efeitos sobre a constituição dos sujeitos, suas subjetividades e expressões sintomáticas. O referencial oferecido pela psicanálise parece vir de encontro a essas questões, já que, para ela, a relação com a lei é constitutiva dos sujeitos.

Transcrita para os termos da presente pesquisa, esta hipótese indica que o recurso a práticas anoréxicas e bulímicas, hoje, pode ser pensado como um efeito das mudanças na relação com a lei, que geram problemas de saúde, na forma do descontrole e da desconexão com as regulações sociais. 


\section{Sobre a coleta dos dados}

Utilizada na antropologia em saúde, a proposta de reconstituição, junto aos entrevistados, de seus "itinerários terapêuticos", se afirma, hoje, como meio para a compreensão da acessibilidade aos serviços de saúde, que envolve não só os aspectos geográficos, econômicos, organizacionais e políticos, mas também os socioculturais e singulares 9 . Nesta pesquisa, a proposta de reconstituição dos itinerários terapêuticos orientou o exercício de uma escuta atenta aos movimentos e motivos de 20 sujeitos em atendimento em um ambulatório universitário de Belo Horizonte, que recebe pacientes provenientes de todo o Estado de Minas Gerais, funcionando em um turno semanal, com capacidade de atenção limitada a aproximadamente 100 pacientes concomitantes. O projeto da pesquisa foi aprovado pelo COEP/ UFMG.

Os entrevistados foram escolhidos por conveniência, conforme sua disponibilidade, no momento em que esperavam por atendimento. Eles foram convidados a participar da pesquisa após os devidos esclarecimentos e o livre consentimento. As entrevistas aconteceram entre setembro e novembro de 2013 e tiveram duração média de 40 minutos, tendo sido gravadas e transcritas pelos pesquisadores.

Entendemos que as versões colhidas junto aos entrevistados são produções mediadas por um estoque de saberes, crenças e receitas adquirido na história do sujeito ${ }^{10}$ e que lhe serve no trabalho, que cada um realiza, de tornar-se alguém frente aos outros, num contexto socialmente estruturado.

Optamos por incitar no entrevistado uma narrativa dos acontecimentos e decisões tomadas, a partir da seguinte questão: "Quando você percebeu que as coisas não iam bem?". Intervimos no curso da narrativa para reconduzir o entrevistado a um relato centrado em sua trajetória de busca (ou não) por tratamento e também no sentido de esclarecer as informações ou as ideias expressas. Aceitamos, no entanto, a direção dos entrevistados quando buscavam justificar ou circunstanciar suas atitudes com relação aos sintomas, desenvolvendo junto a eles a possibilidade de reconstrução ou de ordenação de suas histórias ${ }^{11}$.

As narrativas foram analisadas de forma a identificar os pontos de conexão entre as experiências individuais e o contexto social de sua ocorrência (serviços de saúde, características da prática e do saber médico, características da subjetividade contemporânea), buscando as re- gularidades e as tendências desses itinerários e a lógica que os organiza. Para a apresentação dos resultados, os dados foram ordenados na sequência cronológica dos itinerários percorridos.

\section{Perfil geral do grupo de entrevistados}

Entre os vinte entrevistados, contamos com dezoito sujeitos do sexo feminino e dois do masculino (Quadro 1). Embora a escolha dos sujeitos tenha sido por conveniência, o conjunto deles guarda as características já verificados em estudos epidemiológicos ${ }^{1,2}$ quanto ao sexo e à idade predominante do início dos sintomas.

Ainda que não tenhamos determinado o diagnóstico de cada participante segundo os critérios estabelecidos pelos manuais psiquiátricos, pudemos inferir, a partir dos relatos, que seis deles apresentavam predomínio de sintomas anoréxicos e dez de bulímicos. Os outros quatro já haviam alternado sintomatologia sugestiva ora de anorexia, ora de bulimia, fenômeno frequente nesses quadros ${ }^{12}$.

\section{Aparecimento e funcionalidade do sintoma}

$\mathrm{Na}$ leitura das entrevistas, um primeiro elemento chama a atenção por sua repetição, mas, também, por nos conduzir diretamente ao que deixa sua marca em todo o percurso dos entrevistados: trata-se da recusa do sujeito de qualquer intervenção direta no sentido de impedir ou eliminar suas práticas alimentares. Essa recusa se manifesta, inicialmente, na própria tentativa de ocultação dessas práticas, o que visa preservá-las. Central nesses casos, tal atitude incide diretamente sobre o itinerário terapêutico desses sujeitos, retardando a procura por tratamento.

Embora a discussão etiológica não fosse o foco da nossa pesquisa, a metodologia adotada suscitou, em vários entrevistados, relatos sobre o momento em que as práticas anoréxicas ou bulímicas se instalaram, indicando o que parecia tê-las motivado. Esses dados se tornaram relevantes do ponto de vista dos itinerários terapêuticos, por nos oferecerem acesso à coerência da mencionada recusa do tratamento.

Vários dos entrevistados localizaram o início de suas práticas alimentares como uma resposta, inicialmente funcional, às circunstâncias difíceis em que se encontravam:

Foi do nada! Não sei se foi porque o meu namoro começou a ficar ruim, minha autoestima baixou e eu queria ser melhor, ou se esses dois quilos que eu ganhei a mais me fizeram, sei lá... Ou se 
eu precisava de alguma coisa pra ocupar a minha cabeça. Porque isso ocupa a sua cabeça 24 horas, desde a hora que você acorda. [...] Então, se você quer ocupar a sua cabeça com alguma coisa, tenha anorexia! Porque é, realmente, uma válvula de escape. [...] Só que é uma válvula de escape doente. Igual droga, entendeu? (Ema)

Ema, 18 anos no momento da entrevista, iniciou os sintomas anoréxicos aos 16 e nos explica, nessa passagem, que as coisas não iam bem e que ela encontrou uma saída exilando-se num trabalho obsessivo e solitário sobre a imagem do próprio corpo. Ela rompe com o campo relacional, onde seus problemas se manifestaram, e com o desejo de nele inscrever algo de si.
Uma escolha semelhante é explicitada por Gal, com 18 anos no momento da entrevista e que iniciou práticas bulímicas aos 12 anos:

Eu escondi de todo mundo. Eu ia na psicóloga e não falava do que eu tinha. [...] Por mais que isso seja horrível, isso é confortável para mim, então, sou eu mesma que deixo de falar. (Gal)

Há, em ambos os casos, como em outros, indicações no sentido de que o sujeito encontra, inicialmente, nessas práticas, senão uma solução, pelo menos um meio de tratar seus problemas, como Gal, que se sente, com isso, mais "confortável”. A recusa em abandonar as práticas anoréxicas ou bulímicas torna-se, pois, compreensível: elas são acionadas pelo sujeito como forma de li-

Quadro 1. Perfil geral dos entrevistados.

\begin{tabular}{|c|c|c|c|c|c|c|c|}
\hline Pseudônimo & Sexo* & $\begin{array}{c}\text { Idade na } \\
\text { época da } \\
\text { entrevista }\end{array}$ & $\begin{array}{c}\text { Idade no } \\
\text { início dos } \\
\text { sintomas } \\
\text { (anos) }\end{array}$ & $\begin{array}{l}\text { Idade da } \\
\text { busca por } \\
\text { tratamento } \\
\quad \text { (anos) }\end{array}$ & $\begin{array}{l}\text { Tempo entre início } \\
\text { dos sintomas } \\
\text { e busca por } \\
\text { tratamento (anos) }\end{array}$ & Sintomas iniciais & Sintomas atuais \\
\hline Liz & $\mathrm{F}$ & 10 & 8 & 8 & 0 & bulímicos & bulímicos \\
\hline Eva & $\mathrm{F}$ & 48 & 38 & 38 & 0 & anoréxicos & anoréxicos \\
\hline Lia & $\mathrm{F}$ & 18 & 16 & 17 & 1 & anoréxicos & anoréxicos \\
\hline Mia & $\mathrm{F}$ & 31 & 14 & 20 & 6 & anoréxicos & anoréxicos \\
\hline Ema & $\mathrm{F}$ & 18 & 16 & 18 & 2 & anoréxicos e bulímicos & anoréxicos e bulímicos \\
\hline Dea & $\mathrm{F}$ & 26 & 23 & 23 & 0 & anoréxicos & anoréxicos \\
\hline Ida & $\mathrm{F}$ & 27 & 15 & 22 & 7 & bulímicos & bulímicos \\
\hline Ebe & $\mathrm{F}$ & 19 & 14 & 14 & 0 & anoréxicos & anoréxicos \\
\hline Mel & $\mathrm{F}$ & 33 & 15 & 19 & 4 & bulímicos & bulímicos \\
\hline Giz & $\mathrm{F}$ & 31 & 24 & 29 & 5 & anoréxicos e bulímicos & anoréxicos e bulímicos \\
\hline Gil & M & 14 & 13 & 14 & 1 & bulímicos & bulímicos \\
\hline Lô & $\mathrm{F}$ & 13 & 12 & 12 & 0 & anoréxicos & anoréxicos \\
\hline Iva & $\mathrm{F}$ & 17 & 12 & 13 & 1 & anoréxicos & bulímicos \\
\hline Jú & $\mathrm{F}$ & 26 & 12 & 26 & 14 & bulímicos & bulímicos \\
\hline Ada & $\mathrm{F}$ & 32 & 18 & 26 & 4 & anoréxicos e bulímicos & anoréxicos e bulímicos \\
\hline Teo & M & 40 & 18 & 33 & 15 & bulímicos & bulímicos \\
\hline Jô & $\mathrm{F}$ & 17 & 13 & 13 & 0 & bulímicos & "não tem mais" \\
\hline Isa & $\mathrm{F}$ & 17 & 13 & 14 & 1 & bulímicos & bulímicos \\
\hline Bia & $\mathrm{F}$ & 19 & 16 & 18 & 2 & anoréxicos & anoréxicos e bulímicos \\
\hline Gal & $\mathrm{F}$ & 18 & 11 & 15 & 4 & bulímicos & bulímicos \\
\hline
\end{tabular}

"Sexo: feminino (F) e masculino (M)

Fonte: Elaborado pelos autores. 
dar com dificuldades e angústias, as quais ele não sabe muito bem definir, nem localizar, e que ele esconde, sem delas falar. Entende-se, assim, que o abandono ou a moderação dessas práticas passe pela construção de outra resposta.

Se reconhecemos em nossos dados a funcionalidade dessas práticas, isso não foi sem nos valermos da tese freudiana do sintoma como solução. Para Freud, os sintomas são respostas dos sujeitos a impasses e angústias, que adquirem um sentido ou uma lógica, se consideradas as condições requeridas por cada um para obter e regular sua satisfação pulsional ${ }^{13}$.

As particularidades das anorexias e bulimias contemporâneas como respostas do sujeito têm sido muito pesquisadas no campo da psicanálise, pois sintomas desse tipo vêm se tornando cotidianos na clínica e apresentam muitas diferenças com relação aos neuróticos mais estudados por Freud. Alguns autores contemporâneos localizam essa diferença na dificuldade de decifrar esses sintomas, que parecem opacos à subjetivação. Também é diferente a forma como, nos casos atuais, o sujeito responde a seus impasses por meio de um trabalho sobre a imagem corporal. Isso sugere que existe, ao mesmo tempo, uma dificuldade na constituição dessa imagem e uma inoperância da via oferecida pelo simbólico, o inconsciente e o vínculo social ${ }^{4,14-16}$.

Segundo esses estudos, é nesse ponto, ou seja, na recusa do simbólico, que a clínica se encontra com a atualidade do laço social, marcado pela relativização dos ideais tradicionais e pelo declínio de seu poder de capturar e orientar as pulsões dos sujeitos. Simultaneamente, a imagem ganha destaque na cultura, potencializada pelos meios de comunicação de massa e, como ressaltam algumas análises, passa a ser acessada como meio de construção das individualidades ${ }^{14-16}$. Se, por um lado, a impossibilidade de capturar as pulsões dos sujeitos indica a presença de um obstáculo aos avanços do biopoder, por outro, tenta-se uma regulação através da imagem que, no entanto, se mostra instável.

A clínica hoje tem que se haver com o que fracassa nessa operação de construção do sujeito orientada pelo imperativo das imagens ideais, sem que o registro do simbólico, veiculado no laço social, opere como um regulador. O problema não se encontra na tentativa dos sujeitos de se adaptarem ao ideal estético do corpo magro, mas sim no fracasso dessa tentativa, quando foge de qualquer regulação, para dar lugar a uma satisfação mortífera, em ruptura com o laço social ${ }^{15}$. Afinal, o que faz com que a prescrição onipre- sente da magreza torne-se um imperativo radical para alguns?

Os motivos e as circunstâncias declarados pelos entrevistados para a adoção dessas práticas são variados, mas remetem, todos eles, a situações em que o sujeito se viu premido a responder, a reposicionar-se. Doze dos entrevistados situaram o começo de suas práticas anoréxicas ou bulímicas entre os 11 e 16 anos, ou seja, na puberdade, momento em que ocorrem transformações na imagem do corpo, na forma de manifestação das pulsões sexuais e no estatuto social dos sujeitos, exigindo reformulações, reposicionamentos e escolhas. Como bem diz Rimbaud, o poeta da adolescência, o sujeito se vê premido a "encontrar a fórmula e o lugar" para o que irrompe sem nome e sem forma ${ }^{17}$.

No momento da puberdade ou fora dele, alguns dos entrevistados relataram que se encontravam diante de experiências para as quais ainda não dispunham de resposta. Em alguns deles, o impasse esteve vinculado ao encontro com os enigmas da sexualidade, como sugere o depoimento de Teo, cujo corpo se torna um problema quando, aos 18 anos, ele "vira rapaz":

Desde novinho, eu me sentia gordo, mas não me preocupava com isso. Só quando eu virei rapaz mesmo, comecei a namorar... Muita gente falava que eu era forte, mas eu achava que era gordo. ( $\mathrm{TeO})$

$\mathrm{Na}$ narrativa de Ida, que iniciou com sintomas anoréxicos aos 15 anos, as questões de ordem sexual se misturam ao relato do que poderíamos qualificar como um ataque à imagem corporal, muito recorrente entre os entrevistados. Esse ataque é atribuído a um olhar invasivo que perturba e desorganiza:

... minha prima chegou e eu estava com um short mais curto. Eu estava na casa dela [...]. Ela foi e, simplesmente, fez um pânico: Nossa Ida, você está com estria! É por que você está gorda. [...] você não vai arrumar namorado desse jeito! As pessoas não vão gostar de você assim! (Ida)

Há, ainda, entrevistas em que são referidas experiências de abandono parental, de desordem familiar e também de perdas, situadas na origem dos sintomas ou no seu agravamento. São experiências marcadas pela ausência de um olhar que dê lugar e valor ao sujeito, no campo do Outro. É o que nos conta Jú, cuja mãe se ausentava por meses para trabalhar, deixando-a com o encargo de cuidar da casa e do pai doente:

Eu ficava tentando descobrir sozinha: Por quê? Por que, sem necessidade, a minha mãe se afastou de mim? Porque, quando você perde uma mãe, as- 
sim, por morte, às vezes você tenta entender porque que Deus levou. Mas minha mãe estava viva e tão longe de mim. (Jú)

Também é o caso de Liz, que iniciou com sintomas bulímicos muito precocemente, aos oito anos de idade, após sofrer exposição às intrigas conjugais de seus pais, ficando de fora da cena ocupada inteiramente pelo casal.

Ainda de outro modo, mas indicando que a adoção das práticas alimentares em questão vem como resposta a algo que se apresentou ao sujeito ainda sem nome e sem sentido, há relatos que ressaltam o momento em que se encontrou, contingencialmente, uma resposta:

Teve uns problemas... Primeiro na escola eu era muito zoada porque eu era gordinha. Eu não aceitava. Ficava muito revoltada, ficava nervosa. Ai eu brigava com todo mundo. Até que um dia, eu tava vendo um filme, ai a mulher falou prum cara: Tenho Bulimia. Eu tô assim: nossa que palavra legal! O que é isso? Aí minha mãe foi e me contou. E, no mesmo dia, eu fiz questão de comer e vomitar. Aí, foi daí em diante, por um bom tempo, não sei dizer... Durante uns dois anos fazendo isso. Depois que se tornou hábito, eu comecei a descontar tudo o que eu sentia através do vômito. Se eu tinha raiva, eu descontava no vômito para não quebrar outras coisas. (Jô)

Diante daquilo que suscita seu embaraço, Jô encontra a expressão "tenho bulimia", que serve para nomear o que ela experimenta e modela o escoamento de sua agressividade, definindo o estilo de sua relação com o mundo. Ela, que se encontrava excluída, zoada e sem lugar, se vê, com isso, incluída em um grupo. Observe-se que se trata de uma nomeação cujo sentido permanece obscuro e que não se aproxima da definição médica de transtorno.

Nesse caso, como no relato a seguir, a imagem na televisão e as palavras a ela associadas parecem oferecer a possibilidade de tratamento para aquilo que o sujeito experimentava, sem encontrar um meio de inscrever:

$\mathrm{Na}$ época que eu comecei a ter esses problemas, ninguém sabia que existia bulimia, anorexia. Quando começou aquele Big Brother, que tinha a Leka, ela enfiava o dedo na garganta para emagrecer. Eu me espelhei naquilo. (Ida)

Como forma de intervir sobre a própria imagem, Ida encontra alguém em quem "espelhar-se", perseguindo imperiosamente o ideal da magreza. Ainda que instável, trata-se de uma tentativa de organização pulsional e de construção de um eu, à imagem do semelhante, ali onde algo da constituição de sua própria imagem falhou.

\section{Redes sociais e meios de comunicação de massa}

Os meios de comunicação estiveram presentes nas narrativas de nossos entrevistados, como nos dois casos anteriores, de duas maneiras: ora os blogs e personagens midiáticos são frequentados no sentido de reforçar e aperfeiçoar as práticas alimentares, ora vêm informar, nomeando-as como doenças e indicando a necessidade de tratamento.

Lia nos conta sobre as pesquisas que fazia na internet para descobrir novas técnicas de emagrecimento:

Ai a gente procurava qualquer besteirinha na internet. Achava as coisinhas lá, as ideias para emagrecer, mais dietas. [...] Ah, os blogs, tudo. [...] É, eu mesma pesquisava as dietas malucas lá para emagrecer $10 \mathrm{Kg}$ em uma semana. (Lia)

Segundo Bittencourt e Almeida ${ }^{18}$, os chats, os blogs, os sites são usados não só como forma de compartilhar conhecimentos sobre dietas e comportamentos para atingir o corpo almejado, mas também como uma rede de apoio social para aqueles que estão passando por uma situação estressante e que têm dificuldade de compartilhá -la com quem não vive a mesma experiência. Ao considerarem essa situação como um estilo de vida e não como uma enfermidade, esses grupos se constituem como comunidades coesas, dispostas a aceitar e ajudar novos membros. Ao final, acabam, realmente, promovendo um estilo de vida, uma vez que todos passam a ter atitudes, crenças, objetivos e, frequentemente, corpos semelhantes $^{18}$. O depoimento de Ema corrobora essa descrição:

Eu via as pessoas falando nos blogs que conseguiam ficar não sei quantos dias sem comer... eu ficava com inveja! [...] Eu achava aquilo lindo! [...] Você vê que é capaz de fazer aquilo também. Você vê que é capaz de ter a sua bacia aparecendo e a barriga negativa. [...] Você vê que é capaz daquilo porque você é igual a todo mundo! A diferença entre você e aquela outra pessoa que não consegue fazer isso é a determinação! Se você está determinada a secar, você seca! E eu estava! (Ema)

Para os estudos do campo psicanalítico, essas comunidades se constituem pela identificação comum a um modo de satisfação pulsional. Elas produzem um saber operacional, que potencializa o imperativo do emagrecimento em relações que se caracterizam pela rivalidade. Será preciso que esse saber se mostre, em algum momento, inadequado ao sujeito, para que ele rompa com seu circuito e tenha a oportunidade de inscrever- 
se socialmente de outra forma. A opção por esse tipo de gozo se vincula ao contemporâneo, na medida em que resulta de um tratamento, pela via da imagem, daquilo que se anuncia na angústia, sem a regulação do simbólico, solapado pelas transformações na forma do poder ${ }^{8}$.

A nomeação dessas práticas e sua inscrição como patológicas, a partir de seus efeitos devastadores, se constituem como via para que alguns sujeitos assim se percebam, o que lhes oferece uma identidade confirmada pelo reconhecimento social ${ }^{19}$, sem que isso implique numa compreensão singular do que ocorre.

Eu não sabia o que era. Para mim eu tava normal. [...] Um dia, assistindo televisão, [...], eu vi comentando, uma entrevista com jovens falando sobre isso, sobre a anorexia, que era uma doença, que levava à morte e tal. Aí eu fiquei meio assustada e falei: será que eu tô doente, que eu tô com isso? [...] Nessa época eu fiquei preocupada e tentei dar a volta por cima. Tentei recuperar o peso um pouquinho. (Mia)

O processo de transformação dessas práticas em doenças pelos discursos da saúde suscita o medo de morrer, e sua inscrição social oferece um endereço a esses sujeitos.

\section{Quando a solução se transforma em problema}

Vários dos entrevistados revelaram haver recusado inicialmente o diagnóstico e qualquer tentativa de desviá-los de seus propósitos de emagrecimento. Mesmo diante da reação da família, dos profissionais de saúde e da sociedade em geral, esses sujeitos esquivam-se das intervenções, sonegam o engajamento e, sobretudo, recusam toda abordagem que vise modificar suas práticas alimentares:

Os antidepressivos até que eu tomei normal, foram uns outros medicamentos que iam ajudar mais na parte de alimentação... Eu não tomei alguns remédios que talvez fossem me ajudar a ficar um pouco despreocupada, ao ponto de alimentar melhor. E eu resisti. [...] Só tomei mesmo antidepressivo. Esse aí eu tomo até hoje. (Mia)

Como nesse caso, há relatos que indicam uma instrumentalização da atenção médica e psiquiátrica pelo sujeito, que, afinal, quer eliminar sua depressão ou sintomas físicos desagradáveis, mantendo sua magreza. Mesmo quando o sujeito não se dispõe a um tratamento, o elo que se estabelece com os serviços de saúde tem o importante papel de conservação da vida, podendo constituir-se como via para se iniciar uma abor- dagem diferente da mera tentativa de eliminação do sintoma.

Aqui eu tive muito... Eu considero êxito, porque eu não perdi o principal. Porque eu perdi algumas coisas, tipo assim, a coluna, eu fraturei a coluna, perdi os dentes, mas eu não perdi a vida. (Mia)

Somente o reconhecimento (ou a subjetivação) pelo sujeito de que as práticas bulímicas ou anoréxicas saíram do controle, de que ocorreram perdas físicas e intelectuais, além do medo de morrer levam alguns de nossos entrevistados a uma aceitação do caráter problemático de sua solução:

Eu comecei a estudar, a fazer faculdade, [...] modéstia à parte, eu estava até auxiliando meu professor, mas, um dia, era na semana de prova, eu não estava conseguindo absorver nada. Não entrava nada e, de repente, eu pensei: não estou conseguindo. Vou procurar a professora do apoio psicopedagógico. (Giz)

Durante todo o tempo em que eu emagreci, eu não procurei ajuda nenhuma. [...] o momento em que eu vi que precisava de ajuda, foi depois que eu comecei a ter essas crises [compulsão alimentar seguida de purgação]. Eram fortes. Eu tinha vontade de morrer e no dia em que vi que eu ia fazer uma loucura se eu não falasse nada pra ninguém... Eu ia morrer sozinha. E eu morro de medo de morrer sozinha! Aí, falei. (Ema)

$\mathrm{Na}$ falência de sua solução, esses sujeitos encontrarão na classificação patológica e no acolhimento dos profissionais de saúde um suporte para uma reconstrução. Mas, tanto quanto a ocultação dos sintomas, a recusa do tratamento interfere em seus itinerários, implicando em interrupções, abandonos e trocas frequentes de profissionais. Os desencontros relatados pelos entrevistados na relação com os profissionais de saúde indicam que há limitações na capacidade destes de intervir sobre os processos em curso.

\section{A busca por tratamento}

Para a maioria dos nossos entrevistados, a procura por cuidados dependeu da intervenção de familiares. O tempo entre o início dos sintomas e a procura por ajuda, qualquer que seja ela, foi tanto mais reduzido quanto mais a família se fez presente. De fato, nos casos em que houve maior demora na procura por tratamento, as famílias se encontravam desestruturadas por morte, doenças físicas ou mentais dos pais. Além da família, a escola e o trabalho puderam intervir como mediadores entre esses sujeitos e algum tipo de assistência. 
Uma única entrevistada, Mel, declarou ter, ela mesma, procurado por tratamento. Suas práticas bulímicas se iniciaram aos 15 anos e ela começou um percurso terapêutico intermitente aos 19 anos. Sua história familiar é marcada pela dramática morte do pai, com câncer, quando ela tinha 17 anos. Sua mãe considera que ela procurou a bulimia "com sua própria mão" e, apesar de saber dos sintomas desde que a filha tinha 18 anos, nunca se ocupou com isso.

Levados por familiares ou pelas limitações e graves comprometimentos da saúde, nossos entrevistados revelaram que a busca por tratamento se faz, desde o primeiro momento, junto a profissionais de saúde: onze procuraram inicialmente por médicos, sete procuraram primeiramente por psicólogos e dois por nutricionistas.

Os relatos colhidos a respeito dos encontros desses pacientes com os profissionais de saúde permitem localizar algumas dificuldades, apreendidas aqui unilateralmente, ou seja, na perspectiva de nossos entrevistados e nesse momento de seus itinerários. Segundo relatam, os profissionais procurados reagem em duas direções: ou não se disponibilizam para um acompanhamento, encaminhando ou não para outros profissionais, ou tentam compor parcerias em que se combinam de formas variadas a psiquiatria, a clínica médica, a psicologia e a nutrição.

Os relatos dos que passaram sucessivamente por diversos profissionais sem estabelecer um vínculo, ressaltam o embaraço destes com o seu caso. Alguns atribuem esse embaraço a um desconhecimento:

Fui a uns 8 médicos. Uns perguntavam se eu estava usando drogas, passavam uns calmantes, uns remédios muito fortes. Em vez de melhorar, eu fiquei pior do que já estava. Nenhum médico soube me tratar. [...] É, eu ia, eles passavam, fazia exames e de vez em quando dava nada e às vezes dava. Porque eu não comia, então o meu colesterol subia, meu potássio baixava demais, dava infecção... E eles não sabiam onde estava aquilo. [...] Não podiam passar remédio porque os exames não deram nada. Depois é que começou a dar. (Ebe)

De acordo com Ebe, os clínicos consultados teriam se restringido à necessária verificação dos sinais físicos, encerrando a oferta, no melhor dos casos, por um encaminhamento.

Trajetórias marcadas por encaminhamentos rápidos confirmam o diagnóstico de uma ampla literatura interessada nas características que vem assumindo a prática médica, sobretudo a partir dos anos de 1960 no Brasil. Nela são acentuados o viés técnico e padronizado da atenção médica; o empobrecimento da relação médico-paciente; o abandono da clínica propriamente dita, em prol de orientações epidemiológicas e exames complementares; o esfacelamento da atenção em diversas especialidades, o que não favorece a responsabilização dos profissionais envolvidos ${ }^{20,21}$.

Mas, o estranhamento diante desses pacientes não se restringe aos clínicos, tendo sido descrito também no contato com psicólogos e psiquiatras. Bia, por exemplo, relata que foi levada por sua mãe sucessivamente a cinco psicólogas particulares. Ela explica que teve dificuldades em encontrar especialistas em bulimia, e que as duas que encontrou eram muito caras, acima das possibilidades da família. Já Ema, comenta da seguinte forma o encontro com a psicóloga inicialmente procurada:

Ela me tratava como se eu fosse uma... Uma coisa que eu não era! Sei lá, ela não sabia lidar com isso! Eu acho que essa psicóloga nunca tinha lidado com isso, entendeu? E, quando eu vim nesse psiquiatra, ele virou e falou que não estava apto a me ajudar, que não iria se arriscar comigo e não conseguir me ajudar. (Ema)

Além do estranhamento e do receio, observase que, para grande parte de nossos entrevistados, $\mathrm{o}$ acesso aos profissionais da psicologia e da psiquiatria se faz via rede privada, o que dificulta ou, às vezes, impede a continuidade do tratamento.

Ainda no que se refere aos médicos, alguns entrevistados identificam uma dificuldade, já analisada $^{22}$, em reconhecer a relevância dos aspectos psíquicos do quadro e em operar com eles. É o que observa a seguinte entrevistada:

Quando eu ia na nutróloga, eu sentia ela meio incrédula do lado emocional que as pessoas têm, sabe? Eu sentia que ela procurava explicações apenas físicas e ignorava que, na verdade, o problema era emocional. Então, eu a via como punitiva, ela tentava me educar pelo medo. (Isa)

A educação pelo medo e as medidas de força são referidas também em outras entrevistas, concernindo à conduta de profissionais variados:

A psicóloga era muito... Ela não tinha experiência com anorexia e bulimia. Então... Ela ficava assim: Por que você não come? Vamos comer. Aí ela trazia coisas pra comer na sessão. Mas, eu recusava, eu falava não. [...] Aí, chegou o ponto em que eu não queria mais ir. (Bia)

Eu estava com problema e ele [o clínico] teve a coragem de falar assim: se você não comer, a gente vai ter que enfiar um tubo dentro de você e pôr comida! (Lô)

Tais condutas e as resistências que elas despertam parecem indicar o limite dos saberes em 
reconduzir esses pacientes a uma normalidade alimentar e, muitas vezes, terminam por ser uma tentativa de trocar o imperativo da magreza por outro: “Coma!"

Já a composição de parcerias para a condução do tratamento encontra justificativa na pluralidade de saberes implicados, abarcando tanto a saúde orgânica quanto a mental e permitindo uma divisão de responsabilidades. $\mathrm{O}$ receio dos diversos profissionais em assumir isoladamente o cuidado desses pacientes aparece no caso de Ada, que, tendo encontrado acolhimento junto a uma psicóloga da rede estadual, foi por ela encaminhada ao serviço especializado:

Fiz tratamento um bom tempo com ela. Só que ela achou que eu estava precisando de alguma coisa além... De um acompanhamento que ela não poderia estar fazendo pra mim. Lá não tinha estrutura pra isso, sabe? [...] Aí, ela que fez um encaminhamento pro Hospital das Clínicas. (Ada)

No caso de Isa, com 18 anos no momento da entrevista, e começo dos sintomas aos 13 anos, isso se evidencia de outro modo. Tendo iniciado um tratamento sem sucesso com uma nutricionista, ela passa logo a um acompanhamento psicológico e, mais tarde, a um trabalho com uma nutróloga, que, por sua vez, indica o tratamento psiquiátrico. Apesar dos efeitos positivos iniciais, esta mesma profissional a encaminha ao serviço especializado, dois anos depois, devido ao deslocamento do sintoma para uma rigidez alimentar. Ela acentua na entrevista a recuperação do prazer de comer como uma conquista de seu tratamento atual. Nesse caso, apesar do insucesso inicial de um tratamento nutricional isolado, há, em seguida, composição de parcerias com resultados positivos.

Nas narrativas também localizamos alguns elementos que favorecem o estabelecimento de vínculos com serviços ou profissionais. Sobressaem dentre eles as condutas que não confrontam diretamente os sintomas, no sentido de sua eliminação, conforme discussão em estudo anterior ${ }^{5}$. Posturas mais expectantes visando à construção de uma demanda e de uma relação de confiança facilitam a adesão desses pacientes.

No que se refere à aceitação do tratamento oferecido no ambulatório de especialidade, observa-se que ela é favorecida por uma suposição de saber, sugerida por sua inserção universitária e por sua condição de serviço especializado. Enquanto ambulatório de especialidade, ele também separa seus usuários de outra nomeação, a da loucura, que é recusada, ainda que posta no horizonte pelos medicamentos psiquiátricos.
Contribui igualmente para uma aceitação do acompanhamento no ambulatório, a forma como os pacientes ali chegam: através de informação oferecida por profissionais ou por pessoas qualificadas de sua rede de relações (a psicóloga amiga da patroa, o amigo do chefe do pai, a cuidadora da avó, um programa de rádio), com boas recomendações. Algumas vezes, o atendimento no ambulatório foi citado como o melhor e o último recurso, sendo frequentemente contrastado com os encaminhamentos rápidos, o estranhamento e o desconhecimento percebidos pelos pacientes nos profissionais consultados em seu itinerário.

Outro aspecto que parece favorecer o vínculo com o serviço, embora não imediatamente com o tratamento, é o formato de funcionamento em equipe, que facilita o acesso em um mesmo local a diversos profissionais: o clínico, o psiquiatra, o psicólogo e o nutricionista.

\section{Considerações finais}

A análise dos itinerários terapêuticos de sujeitos com diagnóstico de anorexia e/ou bulimia nervosas nos mostra que eles são a resultante da conjunção social de duas lógicas distintas: uma que organiza a conduta dos pacientes e outra que rege as respostas e os encaminhamentos das instituições de saúde e das famílias. Se essas últimas pressupõem uma busca pela saúde, isso não parece ser o que ocupa prioritariamente os sujeitos em questão, ou, pelo menos, não se trata da mesma versão de saúde.

Conforme vimos, os itinerários analisados são atravessados pela recusa: tanto o estatuto de doença dessas práticas, quanto o tratamento são recusados, o que retarda a procura e prolonga os itinerários terapêuticos. Tal atitude pôde ser vinculada, com o aporte da psicanálise, a uma funcionalidade dessas práticas para seus sujeitos. Elas vêm possibilitar um trabalho sobre a imagem do eu, como forma de resposta ao que o sujeito experimenta como traumático em sua vida. A aceitação ou a adoção da nomeação psiquiátrica muitas vezes não carrega consigo o sentido patológico, vindo, antes, nomear, como nas comunidades virtuais, o trabalho obstinado sobre a imagem do eu. A opção pelo trabalho sobre a imagem relaciona-se, por sua vez, à fragilidade da ancoragem simbólica dos sujeitos, favorecida pela veiculação da lei na forma da norma, que caracteriza o modo de exercício do biopoder até nossos dias. 
A aceitação do estatuto de doença ocorre mediante o reconhecimento das falências física e intelectual e da ameaça à vida. Mas, antes disso, como fogem à normalidade social, essas práticas angustiam o Outro (família, escola ou trabalho), que, então, geralmente, endereça uma demanda aos profissionais de saúde.

A nomeação psiquiátrica oferece, assim, um lugar socialmente qualificado a esses sujeitos, ainda que eles questionem os serviços de saúde, subtraindo-se ao poder das intervenções biomédicas. As conexões desses sujeitos com os serviços de saúde se estabelecem, de início, em função da conservação concomitante de suas práticas alimentares e da vida.

O embaraço dos profissionais de saúde diante desses pacientes se anuncia, como notam os entrevistados, nos encaminhamentos rápidos, na adoção de posturas ameaçadoras ou de força, em que os aspectos psíquicos envolvidos não encontram reconhecimento. A composição de parcerias entre especialistas tem possibilitado a sustentação de tratamentos, pela distribuição de responsabilidades.

Esses itinerários feitos de conexões e desconexões com profissionais, serviços e também com comunidades e personagens virtuais mostraramse governados por imperativos que estão a serviço de uma construção da imagem do eu, por sujeitos que, temporária ou permanentemente, não se servem dos recursos moderadores oferecidos pela incorporação da lei simbólica. Sem a abordagem dessa questão os profissionais de saúde tendem a encontrar, no trato com esses pacientes, os limites de suas intervenções.

\section{Colaboradores}

MB de Carvalho foi autora da proposta de pesquisa e participou da coleta e análise dos dados bem como da redação do texto. AC Val, MMF Ribeiro e LG dos Santos participaram igualmente de todas as etapas da pesquisa, até sua redação final. 


\section{Referências}

1. Miller CA, Golden NH. An introduction to eating disorders. Nutr Clin Pract 2010; 25(2):110-115.

2. Arcelus J, Mitchell AJ, Wales J, Nielsen S. Mortality rates in patients with anorexia nervosa and other eating disorders: a meta-analysis of 36 studies. Arch Gen Psychiatry 2011; 68(7):724-731.

3. Swanson SA, Crow SJ, Le Grange D, Swendsen J, Merikangas KR. Prevalence and correlates of eating disorders in adolescents: results from the national comorbidity survey replication adolescent supplement. Arch Gen Psychiatry 2011; 68(7):714-723.

4. Le Breton D. Adeus ao corpo: antropologia e sociedade. Campinas: Papirus; 2007.

5. Val AC, Carvalho MB, Campos RO. Entre o singular e o coletivo: a experiência de um serviço na abordagem das anorexias e bulimias. Physis 2015; 25(1):99-119.

6. Val AC, Cunha CF, Ferreira RA, Carvalho MB. Um caso de anorexia nervosa: a condução do tratamento. Rev Latinoam Psicopatol Fundam 2014; 17(3):485-500.

7. Foucault M. Em defesa da sociedade. São Paulo: Martins Fontes; 1999.

8. Santos TC, Santiago J, Martello A, organizadores. Os corpos falantes e a normatividade do supersocial. Rio de Janeiro: Cia de Freud; 2014

9. Cabral ALLV, Martinez-Hemáez A, Andrade EIG, Cherchiglia ML. Therapeutic itineraries: state of the art of scientific production in Brazil. Cien Saude Colet 2011; 16(11):4433-4442.

10. Rabelo MC. Experiência de doença e narrativa. Rio de Janeiro: Editora Fiocruz; 1999.

11. Miranda L, Campos RTO. Ethical guidelines for working in mental health: a psychoanalytic reading. Rev Latinoam Psicopatol Fundam 2013; 16(1):100-115.

12. Eddy KT, Dorer DJ, Franko DL, Tahilani K, Thompson-Brenner H, Herzog DB. Diagnostic Crossover in Anorexia Nervosa and Bulimia Nervosa: Implications for DSM-V. Am J Psychiatry 2008; 165(2):245-250.
13. Freud S. Conferência XVII: O sentido dos sintomas. In: Freud S. ESB, v. XVI. Rio de Janeiro: Imago; 1996. p. 265-279.

14. Recalcati M. La última cena: anorexia y bulimia. Buenos Aires: Del cifrado; 2007.

15. Eidelberg A, Godoy C, Schejtman F, Dafunchio NS. Porciones de nada. La anorexia y la época. Buenos Aires: Del Bucle; 2009.

16. GraciaArnaiz M, Comelles JM, Bernal M, organizadores. No comerás: narrativas sobre comida, cuerpo y género en el nuevo milenio. Barcelona: Icaria Editorial; 2007.

17. Lacadée P. $O$ despertar e o exílio: ensinamentos psicanalíticos da mais das delicadas transições, a adolescência. Rio de Janeiro: Contra Capa; 2011.

18. Bittencourt LJ, Almeida RA. Eating disorders: disease or lifestyle? Psicol Amp Soc 2013; 25(1):220-229.

19. Rose N. A política da própria vida: biomedicina, poder e subjetividade no século XXI. São Paulo: Paulus; 2013.

20. Helman CG. Cultura, saúde e doença. Porto Alegre: Artmed; 2009.

21. Donnangelo MCF. Medicina e sociedade. O médico e seu mercado de trabalho. São Paulo: Pioneira; 1976.

22. Guedes CR, Nogueira MI, Camargo Júnior KR. Vague and diffuse symptoms in biomedicine: a review of the literature. Cien Saude Colet 2008; 13(1):135-144.

Artigo apresentado em 05/06/2015

Aprovado em 26/10/2015

Versão final apresentada em 28/10/2015 
